\title{
Enhanced in vitro model of the CSF dynamics
}

\author{
Anne Benninghaus ${ }^{1 *} \mathbb{0}$, Olivier Balédent ${ }^{2}$, Armelle Lokossou ${ }^{2}$, Carlos Castelar ${ }^{3}$, Steffen Leonhardt ${ }^{3}$ \\ and Klaus Radermacher ${ }^{1}$
}

\begin{abstract}
Background: Fluid dynamics of the craniospinal system are complex and still not completely understood. In vivo flow and pressure measurements of the cerebrospinal fluid (CSF) are limited. Whereas in silico modeling can be an adequate pathway for parameter studies, in vitro modeling of the craniospinal system is essential for testing and evaluation of therapeutic measures associated with innovative implants relating to, for example, normal pressure hydrocephalus and other fluid disorders. Previously-reported in vitro models focused on the investigation of only one hypothesis of the fluid dynamics rather than developing a modular set-up to allow changes in focus of the investigation. The aim of this study is to present an enhanced and validated in vitro model of the CSF system which enables the future embedding of implants, the validation of in silico models or phase-contrast magnetic resonance imaging (PC-MRI) measurements and a variety of sensitivity analyses regarding pathological behavior, such as reduced CSF compliances, higher resistances or altered blood dynamics.
\end{abstract}

Methods: The in vitro model consists of a ventricular system which is connected via the aqueduct to the cranial and spinal subarachnoid spaces. Two compliance chambers are integrated to cushion the arteriovenous blood flow generated by a cam plate unit enabling the modeling of patient specific flow dynamics. The CSF dynamics are monitored using three cranial pressure sensors and a spinal ultrasound flow meter. Measurements of the in vitro spinal flow were compared to cervical flow data recorded with PC-MRI from nine healthy young volunteers, and pressure measurements were compared to the literature values reported for intracranial pressure (ICP) to validate the newly developed in vitro model.

Results: The maximum spinal CSF flow recorded in the in vitro simulation was $133.60 \mathrm{ml} / \mathrm{min}$ in the caudal direction and $68.01 \mathrm{ml} / \mathrm{min}$ in the cranial direction, whereas the PC-MRI flow data of the subjects showed $122.82 \mathrm{ml} / \mathrm{min}$ in the caudal and $77.86 \mathrm{ml} / \mathrm{min}$ in the cranial direction. In addition, the mean ICP (in vitro) was $12.68 \mathrm{mmHg}$ and the pressure wave amplitude, $4.86 \mathrm{mmHg}$, which is in the physiological range.

Conclusions: The in vitro pressure values were in the physiological range. The amplitudes of the flow results were in good agreement with PC-MRI data of young and healthy volunteers. However, the maximum cranial flow in the in vitro model occurred earlier than in the PC-MRI data, which might be due to a lack of an in vitro dynamic compliance. Implementing dynamic compliances and related sensitivity analyses are major aspects of our ongoing research.

Keywords: In vitro modeling, CSF dynamics, Compliance, NPH

\footnotetext{
*Correspondence: benninghaus@hia.rwth-aachen.de

${ }^{1}$ Chair of Medical Engineering, Helmholtz-Institute for Biomedical Engineering, RWTH Aachen University, Pauwelsstraße 20, 52074 Aachen,

Germany

Full list of author information is available at the end of the article
} 


\section{Introduction}

The CSF is an aqueous fluid containing small concentrations of various proteins, glucose and electrolytes which surrounds the central nervous system and, consequently, serves as a 'lymphatic' system and a mechanical shock absorber. The rates of CSF production and absorption are usually in equilibrium. However, the exact locations for production and absorption are still being discussed $[1,2]$. In addition, the fluid dynamics of the craniospinal system are determined primarily by the rapid in-and outflow of blood to the cranial compartment, driving the fluid to the more distensible spinal compartment in systole and returning to the cranium in diastole [3-6].

If the CSF dynamics are disturbed, due to aging or changes in blood dynamics, compliance, production and absorption, or resistance, and pathological conditions can be observed by measuring abnormal intracranial pressure (ICP) or CSF flows. Normal pressure hydrocephalus $(\mathrm{NPH})$ is a pathological condition, which predominantly occurs in the elderly ( 65 years + ), and results in a pathological enlargement of the brain ventricles without an attendant rise in mean ICP. The symptoms of gait ataxia, urine incontinence and dementia, which can occur in the elderly, make the diagnosis difficult [7]. According to Hakim et al. up to $10 \%$ of all demented patients might be suffering from NPH [8]. However, the pathogenesis is still not understood and, therefore, effective therapy for NPH patients is still lacking. Many hypotheses suggest that biomechanical alterations due to aging upset the craniospinal dynamics and, thereby, play an important role in the formation of NPH [9-15].

There are different ways to investigate CSF dynamics and particularly the onset of NPH. Phase-contrast magnetic resonance imaging (PC-MRI) is an established tool to investigate the CSF or blood flow in vivo. A recent study on the accuracy of PC-MRI showed that the measuring error of a pulsatile flow is less than 10\% [16]. On the one hand, in vivo data, such as flow measurements, provide information about the healthy and pathological conditions. On the other hand, this data is limited, and it is difficult to draw conclusions about the origin of the diseases. Furthermore, sensitivity analyses on the living organism are not possible, and the mechanical properties of the central nervous system tissue degenerate postmortem. Therefore, animal studies are often used to provide insights concerning issues such as absorption distribution or opening pressures [17]. In addition to the ethical aspects, transferability to humans must be taken into account, especially if hydrodynamics are considered, since the upright gait of humans differs fundamentally from the quadruped walk of most mammals. Moreover, the main knowledge about fluid mechanics originates from chemical, cellular or tissue aspects, although pathological conditions may only be derived from disturbed fluid mechanics.

Modeling (in silico or in vitro) the craniospinal system is an effective tool for analyzing the CSF system. There are varieties of in silico models which are commonly used for parameter examinations [15]. A distinction is made between computational fluid dynamics and lumped parameter models, which usually focus on a specific question. Lumped parameter models are often imaged by mechanical or electrical analogies but cannot map the spatial resolution flux distribution [18]. Computational fluid dynamic models calculate spatially resolved information of the system dynamics, such as pressure, flow or mass transport, but require high performance computing [19]. Hence, the hypothesis determines the appropriate kind of simulation. Nonetheless, there is no numerical tool for the entire CSF system and, additionally, simulation models cannot test implants.

In vitro models enable sensitivity analyses as well as the integration and testing of implants, such as shunt testing systems $[20,21]$. Furthermore, there are a number of in vitro models for the craniospinal system extant, such as an artificial spinal canal $[22,23]$ or the modeling of cerebral vascular vessels [24]. In addition, two models have focused on the depiction of the craniospinal system as a whole. The model of Bouzerar et al. aims particularly at the investigation of the transmission of the blood pulsation to CSF dynamics and allows flow studies with altered hydrostatics to be made [25]. However, adjustable compliances and flow resistances were not considered. The second model by Bottan et al. focuses on the anatomically correct imaging of the cranial space with two adjustable compliance units, without the consideration of an attached spinal canal [26]. Thus, no hydrostatic investigations could be conducted.

Consequently, our goal was to design a model of the CSF dynamics which enables the investigation of its aging process and pathological transformation by conducting a variety of sensitivity analyses. We designed an in vitro model including brain parenchyma, cranial and spinal subarachnoid space (SAS), as well as adaptable compliances, blood pulsation and resistances to examine the dynamics. In contrast to in silico models of the CSF dynamics, our model also enables the future embedding and testing of alternative therapy methods. Moreover, the model can be used to validate simulation models. [27]

\section{Materials and methods}

The proposed phantom model design approach incorporates adjustable blood pulsation characteristics, cranial and spinal compliances, hydrostatics and flow resistance. These parameters can be varied to simulate physiological and pathological situations. The schematic set-up 


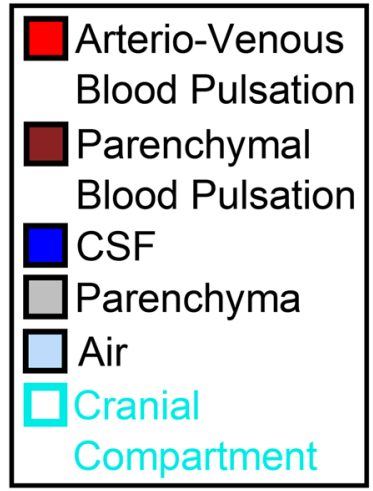

Arterio-Venous

Parenchymal Blood Pulsation CSF $\square$ Parenchyma Cranial Compartment

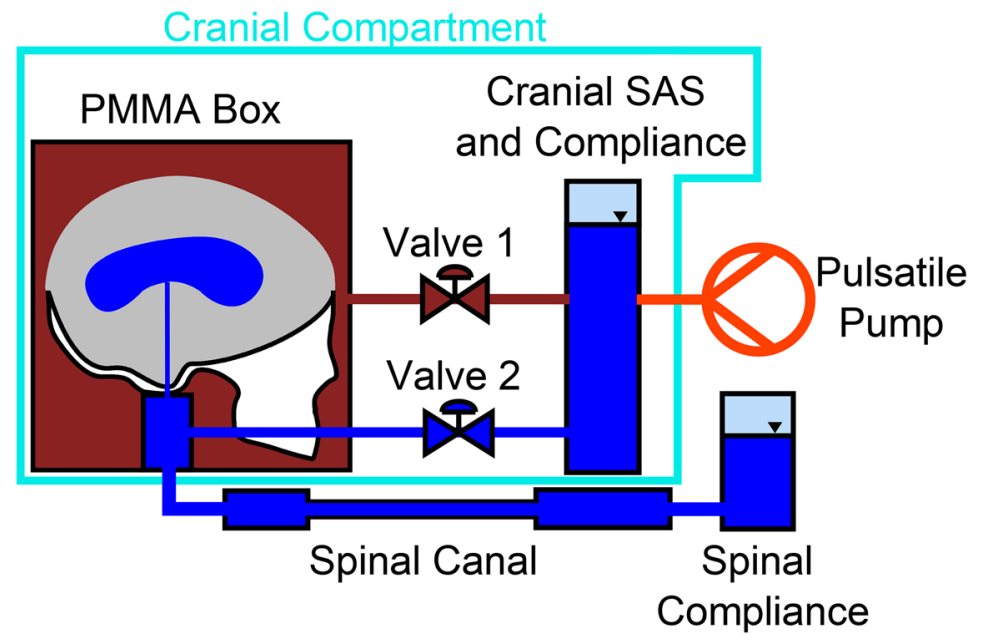

Cranial Compartment

Fig. 1 Schematic drawing of the experimental setup with a PMMA box containing the parenchyma (gray) with an enclosed ventricular system (blue), the cranial subarachnoid space and the spinal canal. The arteriovenous (AV) blood flow is reproduced by a pulsatile pump (red) connected to the cranial compliance chamber. Valve 1 adjusts the pulsation from the cranial SAS to the parenchyma, transmitted by the surrounding water in the box (dark red) and Valve 2 represents the resistance of the cranial SAS. Cranial and spinal compliance chambers are filled with air (light blue) in addition to the CSF (dark blue)

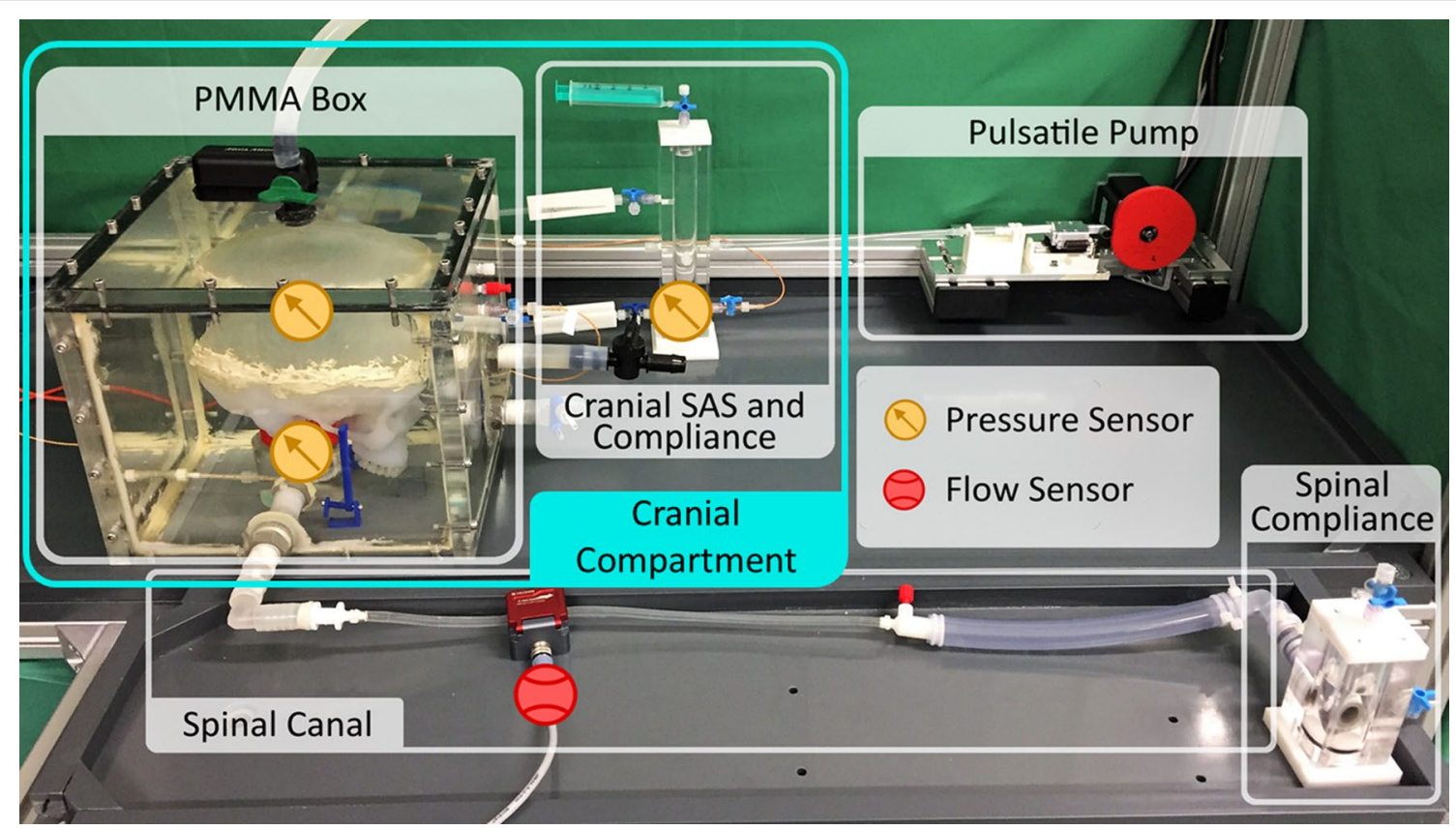

Fig. 2 Experimental lab test bench. Three tip catheter pressure sensors (yellow) are placed inside the silicone parenchyma (measurement of ICP), the cistern and the compliance chamber of the cranial SAS. The ultrasound flow sensor (red) is attached at the upper part of the spinal canal (corresponding to the C2-C3 level)

is shown in Fig. 1. There are three main CSF compartments connected to each other in the phantom model: The sealed polymethylmethacrylate (PMMA) box containing a parenchyma model with an enclosed ventricular system, the cranial SAS and the spinal canal. In addition, both cranial and spinal SAS are connected to separate compliance chambers. All compartments are filled with degassed water to represent the CSF. The corresponding lab test bench is shown in Fig. 2. As a first approach, production and absorption were neglected in the model 
due to the small flow volume compared to blood and CSF pulsations. A detailed list and part drawings of the components are available on request from the authors.

\section{Ventricular system and SAS}

The PMMA box provides a rigid containment and accommodates a simplified ventricular system cast in a silicone brain (Sylgard 527, A\&B Dielectric Silicone Gel, Dow Corning, Midland, Michigan). The parenchyma is glued to a plastic lower part of the skull, which is mounted to the bottom of the box. Whereas the skull prevents the silicone brain from ascending in the surrounding water due to density differences, it does not model a closed cranium. The ventricular system is modeled as one kidneyshaped cavity with a volume of $35.2 \mathrm{ml}$ which combines both lateral and the third ventricle volumes. The cranial SAS is modeled by the cranial compliance chamber and the resistance (Valve 2). The pulsation of the pump is transmitted to the fluid in the PMMA box surrounding the parenchyma via the cranial compliance chamber and Valve 1. Water is a Newtonian fluid which is incompressible and transfers pulsatile energy directly into the CSF system. The flow from the cranial SAS into the PMMA box results in compression of the parenchyma and, thus, in a pulsating aqueductal flow. Furthermore, Valve 2 (Fig. 1) simulates an adjustable flow resistance within the cranial SAS. The other valve is situated between the cranial compliance chamber and the PMMA box and controls the pulsatile compression of the brain parenchyma (Fig. 1, Valve 1 (red)).

In a similar way to the cranial SAS, the flow resistance in the spinal canal plays an important role in the CSF dynamics. Therefore, the spinal canal is modeled by tubes with different diameters, which are connected to create an overall physiological hydraulic diameter varying from 5 to $15 \mathrm{~mm}$ (according to Loth et al. [28]). At the same time, the overall length of the spinal canal corresponds to a characteristic anatomical length and can be used to investigate the impact of hydrostatic changes on the CSF dynamics.

\section{Pulsatile pump}

Vascular flow dynamics have an impact on the cranial and spinal CSF flow and pressure and are considered to majorly affect pathological conditions, such as NPH. During systole, $15 \%$ of the cardiac output is transferred to the brain via the carotis interna and carotis vertebralis. Subsequently, the blood leaves the cranial compartment through the veins $[3,9]$.

The arteries can expand and, therefore, flatten the pulsatile flow (Windkessel effect), whereas the veins can collapse and increase the cranial compliance. The subtraction of these two flows depicts the arteriovenous
(AV) flow. Furthermore, the Monroe Kellie Doctrine states that the volume inside the cranium is invariable and remains the same throughout systole and diastole, because it is limited by the rigidity of the skull. By modeling the AV flow with a stroke volume (SV) of approximately $0.8 \pm 0.2 \mathrm{ml}$ into the cranium [14], the CSF shifts accordingly. Therefore, the change in blood volume directly affects the CSF dynamics in the cranial compartment. Boundary conditions in the spinal compartment differ from the cranial compartment. Although the spinal canal is also supplied with a pulsating blood flow, the spinal pulsation is much lower [29] and is, thus, negligible compared to the cranial pulsation.

We designed a cam plate-driven piston pump to reproduce the dynamic effects of the blood vessels on the CSF system. The assembly consists of three units: the drive unit, the piston and the cylinder (Fig. 3). The core piece is the drive unit, composed of a stepping motor and a controller (ST6018L3008-A and SMCI33-2, nanotec, Feldkirchen, Germany), and the cam disc. The piston unit, in combination with the cam roller and the defined outer cam contour, converts the rotary motion into correspondingly defined translational motion. The cylinder and the piston are parts of a common syringe $(2 \mathrm{ml})$, which is connected to the cranial SAS through a polyvinyl chloride tube. The vascular effect on the CSF system can be changed easily by altering the disk contour according to the AV flow curves. The arterial and venous blood flow was measured at the $\mathrm{C} 2-\mathrm{C} 3$ level with PC-MRI. The venous outflow measured was shifted, so that the volume of the arterial inflow matched the venous outflow volume (Fig. 4). The AV flow is transferred to a cam disk using the hodograph transformation [30]. The resulting cam discs and the other red colored parts of the pump (Fig. 3) were manufactured using a FDM 3D printer (Ultimaker 3, Ultimaker B.V., Geldermansen, Netherlands). A connection of the PMMA box and the cranial SAS is established to model the variable effect of the parenchymal compression due to the AV blood pulsation by using another polyvinyl chloride tube and an adjustable valve (Valve 1 in Fig. 1).

\section{Compliance unit}

Compliance is defined as the ratio of volume (V) to pressure (p) change and enables the system to accommodate a change of volume with an attendant pressure change [31].

$$
C=\frac{d V}{d p}
$$

The compliance of the CSF system is based on vascular and tissue effects. Vascular effects on cranial compliance are associated mainly with collapsing veins [32]. 


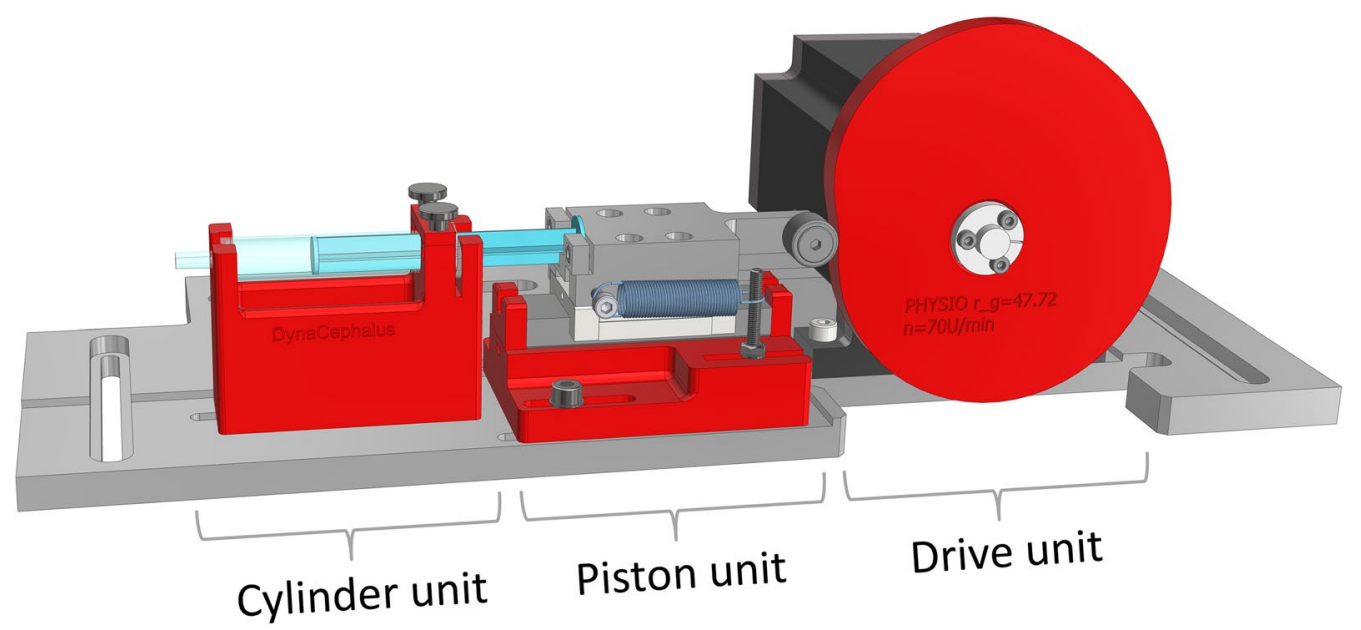

Fig. 3 Cam plate driven piston pump. CAD model of the pulsatile pump, consisting of a cylinder unit, a piston unit and a drive unit with a patient-specific 3D-printed cam plate

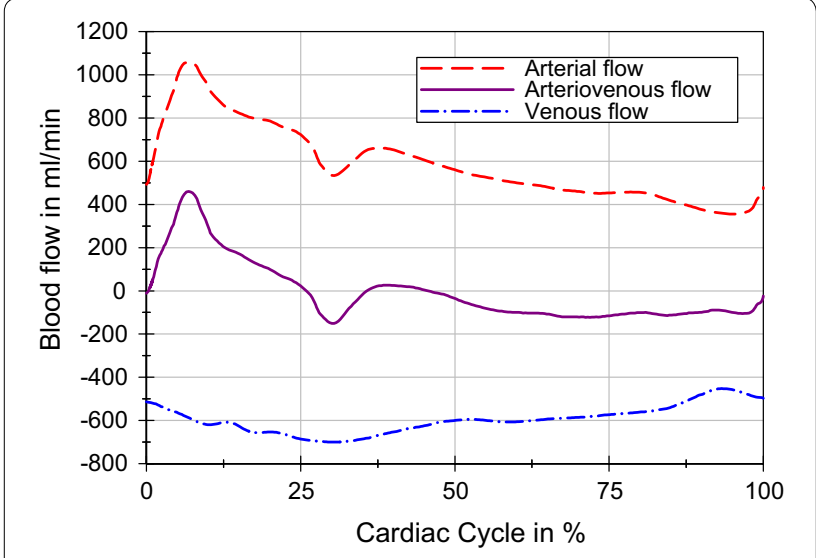

Fig. 4 Pulsatile blood flow. The arterial inflow (red) and venous outflow (blue) add up to the AV flow-based (purple) PC-MRI measurements (data derived from ElSankari et al. [38])

However, the vascular compliance of arteries during the cardiac cycle $(\mathrm{CC})$ also has an impact on the profile of blood pulsation [33]. Since the cranium is a rigid box, the vascular effects primarily affect the cranial compartment. In addition, the distal dural sac is the most compliant tissue in the CSF system [32]. Therefore, the division into a cranial and spinal compartment, adding up to the total compliance, is very common.

$$
C_{\text {total }}=C_{\text {cranial }}+C_{\text {spinal }}
$$

However, there is still a debate concerning the distribution of the compliance [31, 34-36]. Consequently, two independent adjustable compliance units were connected to the model representing the cranial and the spinal compliant behavior. As a first approximation, these units,
Table 1 Compliance values and distributions in the in vitro model. Derived from Zweckberger et al. [60] and Tain et al. [31]

\begin{tabular}{llll}
\hline Compliance & Total & Cranial & Spinal \\
\hline Value in $\mathrm{ml} / \mathrm{mmHg}$ & 1.15 & 0.31 & 0.84 \\
Distribution in \% & 100 & 27 & 68 \\
\hline
\end{tabular}

filled with water and air, model a static compliance. Since air can be described as an ideal gas, the following equation is used:

$$
p_{0} \cdot V_{0}^{\lambda}=p_{1} \cdot V_{1}^{\lambda}
$$

with $\lambda=1.4$ indicating the isentropic exponent 0 the initial and 1 the resulting state. Combining Eqs. (1) and (3) and differentiating regarding pressure results in an equation for the compliance, which is only dependent on the pressure and the initial air volume in the container:

$$
C=\frac{1}{\lambda} \sqrt[\lambda]{p_{0}} V_{0}\left(p_{1}\right)^{-\frac{1+\lambda}{\lambda}}
$$

Considering the pressure and its amplitude in the different compartments, the compliance can easily be adjusted by changing the initial volume of air. The setup parameters were chosen to simulate a physiological compliance in a supine position with a distribution of $0.31 \mathrm{ml} / \mathrm{mmHg}$ (27\%) for the cranial and $0.84 \mathrm{ml} / \mathrm{mmHg}(68 \%)$ for the spinal compliance compartment (Table 1). Changing the position from supine to an upright position affects hydrostatic pressures and, thus, the compliance has to be taken into account concerning hydrostatic behavior. 


\section{Data Acquisition system - in vitro measurement}

There are three tip catheter pressure sensors (NEUROVENT, Raumedic, Helmbrechts, Germany), measuring pressures between -40 and $400 \mathrm{mmHg}$ with an mean zero drift after 5 days of $0.6 \mathrm{mmHg}$ [37]. The sensors were placed inside the silicone parenchyma (ICP), the cistern and the compliance chamber of the cranial SAS. In addition, an ultrasound flow meter (Sonoflow CO.55/060, Sonotec, Halle, Germany) was located at the beginning of the spinal canal (similar to $\mathrm{C} 2-\mathrm{C} 3$ level) to assess the cervical CSF flow in both directions (cranial/caudal, Fig. 2). The ultrasound technique enabled a contactless measurement, yet with an accuracy of $6 \mathrm{ml} / \mathrm{min}$ according to the manufacturer information. Due to the deviation of the flow value, the measurement was recorded over nine CCs. In addition, all sensors were connected to the computer data logging system NI cDAQ-9174 with the module NI 9237 for the pressure sensors and the module NI 9230 for the ultrasound flow sensor, which enabled the signal outputs to be recorded simultaneously and analyzed with the corresponding manufacturer software DIAdem (National Instruments, Austin, Texas, USA). All in vitro results were measured simulating 70 heart beats $/ \mathrm{min}$ in a supine position. The pulsatile pump rotated twice before the recording starts to avoid a ramping effect.

\section{Data Acquisition system-in vivo measurement}

In a previous study, CSF flow curves were calculated in nine healthy young adult volunteers on a $3 \mathrm{~T}$ machine using $2 \mathrm{D}$ fast cine PC-MRI pulse sequence with retrospective peripheral gating to reconstruct 32 frames covered the entire CC [3,38]. The MRI parameters were as follows: two views per segment; flip angle: $20^{\circ}$; field-of-view (FOV): $14 \times 14 \mathrm{~mm}^{2}$; matrix: $256 \times 128$; slice thickness: $5 \mathrm{~mm}$; one excitation. Velocity (encoding) sensitization was set to $5 \mathrm{~cm} / \mathrm{s}$. A sagittal scout view was used as a localizer. The selected acquisition plane was perpendicular to the presumed flow direction at the cervical level between the second and the third vertebra. Duration of the acquisition was around 2 min. Post processing was done with our homemade software [3].

The in vivo graphs (AV and CSF flow) are not synchronized in time, since the data was taken from different subjects. In vitro flow measurements were compared to the PC-MRI flow recordings. The time axes of the in vitro recordings correspond to the in vivo CSF flow data. The procedure of the flow measurements is shown in Fig. 5. Moreover, the in vitro ICP was compared with literature data and plotted from minimum to minimum.

\section{Results}

\section{In vivo flow-PC-MRI}

The flow curves in Fig. 6a show the results of the PC-MRI measurements of the volunteers representing the healthy population $[3,38]$. Since their heart rates varied, data was adjusted to one $\mathrm{CC}$. The cervical flow was measured in $\mathrm{ml} / \mathrm{min}$ with the flow direction from cranial to caudal defined as positive and the reverse flow as negative. The maximum PC-MRI flow was $122.86 \mathrm{ml} / \mathrm{min}$ in the caudal and $77.86 \mathrm{ml} / \mathrm{min}$ in the cranial direction (Table 2). Furthermore, the SV were calculated and compared to physiological SVs in the spinal canal reported in literature. The SV was computed by the integration of the mean flow and results per CC in $0.385 \mathrm{ml}$ for the PC-MRI measurements (Table 3).

\section{In vitro flow-ultrasound flow sensor}

The resistance, compliance and blood dynamics in the system influence the results of the in vitro measurement. Therefore, the parameter setup was not changed during the flow and pressure recordings. The AV flow is shown in Fig. 4 and the compliance volume and distribution in Table 1.

The in vitro cervical flow was measured over nine CCs and is displayed in Fig. 6b, showing the range of the flow recorded by the ultrasound sound meter. The maximum of the mean in vitro measurement was $133.60 \mathrm{ml} / \mathrm{min}$ in the caudal and $68.01 \mathrm{ml} / \mathrm{min}$ in the cranial direction (Table 2) with a mean SV of $0.312 \mathrm{ml} / \mathrm{CC}$ (Table 3). The point in time at which the flow in the cranial direction was maximal (the minimums of the plots in Fig. 6), did not coincide for the two measuring methods. Taking the maximum caudal flow as the start and end $(0$ and $100 \%$, respectively), the maximum in vitro flow towards the cranium measured occurred at around $25 \%$ of the CC, whereas the in vivo maximum was at approximately $63 \%$, the latter varying by about $10 \%$ with the individual data.

\section{Pressure curves}

The ICP, measured inside the ventricular system over one $\mathrm{CC}$ in a supine position is shown in Fig. 7. There are three lines: The two dashed lines represent the maximal and minimal pressure progression and the continuous line, the mean ICP. The arithmetic mean ICP value over nine CCs was $12.68 \mathrm{mmHg}$. The maximum ICP was $14.98 \mathrm{mmHg}$ and the minimum was $10.02 \mathrm{mmHg}$. Furthermore, two pressure peaks were identified with a ratio of (P2:P1) 0.792 and a mean wave amplitude (MWA) of the first pressure peak at $4.86 \mathrm{mmHg}$. Control measurements with the other two pressure sensors (Cistern, Cranial SAS) showed no significant deviations. 


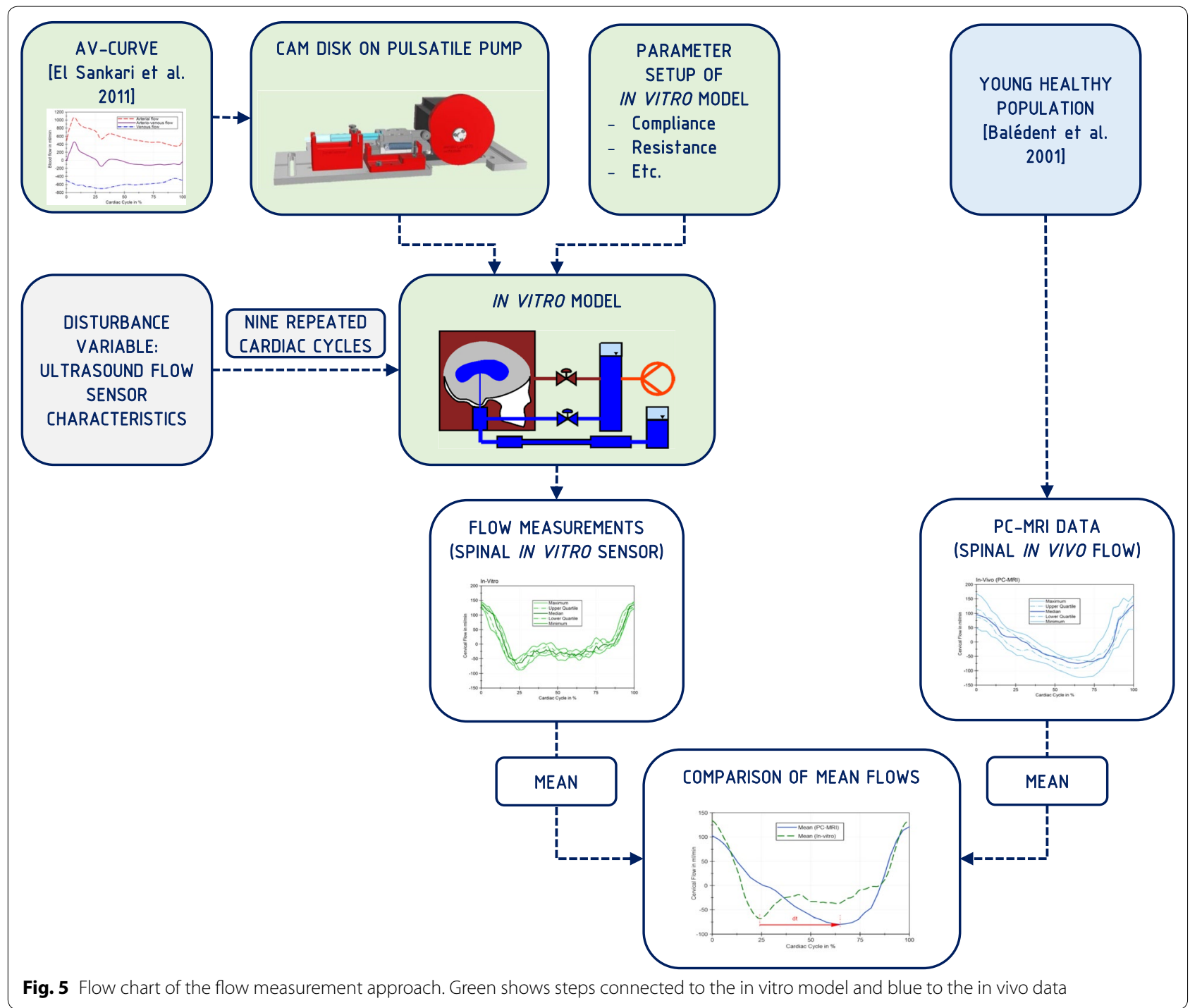

\section{Discussion}

\section{Flow measurements}

The extreme values of the in vitro flow measurements are in good agreement with the PC-MRI data as they were within the tolerance range of the PC-MRI measurements. Furthermore, other research groups support the recorded flow measurements with similar flow values in both directions [39, 40]. Additionally, both curves showed a typical steep rise during systole. Moreover, the occurrence of minimal flow in the in vitro measurement developed ahead of the PC-MRI flow minimum (dt in Fig. 8). This could occur due to a return oscillation or reflection of the arterial pulse wave, since only a static compliance, represented by the air in the compliance chambers, has been taken into account so far in the experimental setup. However, the brain and the tissue surrounding the craniospinal system has viscoelastic properties that require a timedependent or dynamic compliance [15, 32, 41, 42].

In addition, the spinal SV of the phantom $(0.312 \mathrm{ml} /$ $\mathrm{CC})$ was in the same range as the PC-MRI measurements of healthy volunteers $(0.385 \mathrm{ml} / \mathrm{CC})$, defining a physiological range for the SV from 0.272 to $0.699 \mathrm{ml} / \mathrm{CC}$ [14, 38, 39, 43-45] (Table 3).

\section{Pressure measurements}

The in vitro results of ICP are compared with literature values as no ICP measurements have been performed on the healthy population undergoing PC-MRI measurements. The mean ICP in a horizontal position was $12.68 \mathrm{mmHg}$ and is, thus, in a physiological range [6, 46-49]. Considering there is a lack of data on the maximum ICP amplitude, because invasive ICP recordings 

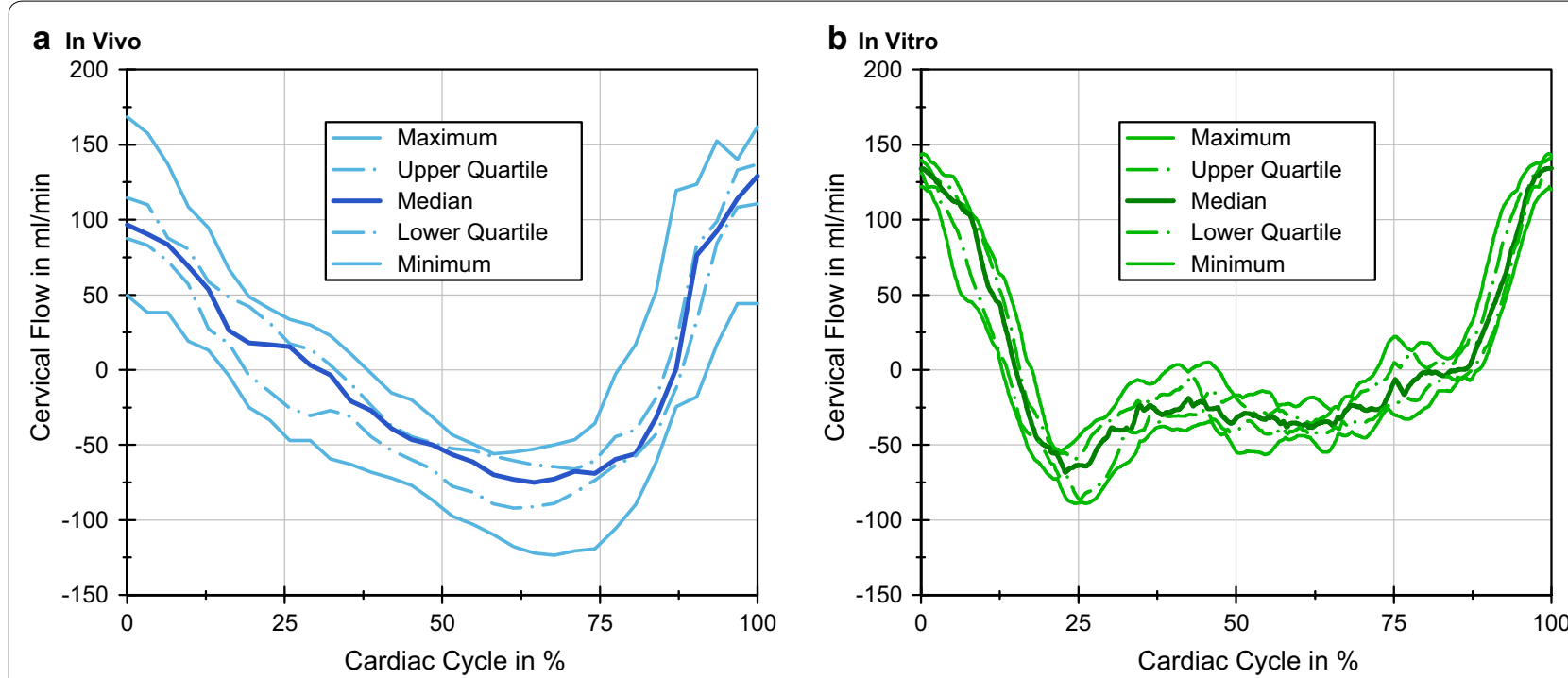

Fig. 6 a PC-MRI (In vivo) measurements of the spinal CSF flow at the C2-C3 level. The range of the flow measurement and the median flow of nine young healthy volunteers is shown. $\mathbf{b}$ In vitro measurements of the spinal CSF flow at the C2-C3 level. The range of the ultrasound flow measurement of nine cardiac cycles (CC) is shown

Table 2 Mean bidirectional maxima CSF flow in the spinal canal divided into in vitro and in vivo (PC-MRI) data with maximal and minimal deviations

\begin{tabular}{|c|c|c|c|}
\hline Measurement & Flow direction & Mean in $\mathrm{ml} / \mathrm{min}$ & $\begin{array}{l}\text { Deviations } \\
\text { in } \mathrm{ml} / \mathrm{min}\end{array}$ \\
\hline \multirow[t]{4}{*}{ In vivo } & $Q_{\text {cranial-caudal }}$ & 122.82 & +29.61 \\
\hline & & & -38.27 \\
\hline & $Q_{\text {caudal_cranial }}$ & -77.86 & +22.02 \\
\hline & & & -21.28 \\
\hline \multirow[t]{4}{*}{ In vitro } & $Q_{\text {cranial_caudal }}$ & 133.60 & +10.31 \\
\hline & & & -11.67 \\
\hline & $Q_{\text {caudal_cranial }}$ & -68.01 & +14.43 \\
\hline & & & -21.09 \\
\hline
\end{tabular}

Table 3 Spinal stroke volume (SV) in $\mathrm{ml}$ per cardiac cycle (CC)

\begin{tabular}{lll}
\hline & Stroke volume & References \\
\hline In vitro & 0.312 & Integration of flow \\
In vivo & 0.385 & Integration of flow \\
Physiological & $0.272-0.699$ & {$[14,38,39,43-45]$} \\
\hline
\end{tabular}

are not performed on healthy individuals, the measurement of the maximum amplitude cannot be classified as physiological. However, the MWA of NPH patients, for instance, is used to categorize patients into two groups: Those who respond to the placement of a shunt and those who do not $[50,51]$. The pulse wave amplitude in the in vitro model was below $5 \mathrm{mmHg}$ and is, therefore, still in a similar value range as the data reported. An MWA above $5 \mathrm{mmHg}$ would be considered conspicuous. Furthermore, an additional dynamic compliance would further decrease the MWA. Finally, the pressure curves demonstrated the stability of the model and the pressure measurement, since the maximum and minimum curves deviated by only $0.148 \mathrm{mmHg}$ in the extreme values over various CCs.

\section{Limitations and prospects}

The validation of the model presented can only be applied in a supine position, because all measurements (in vivo and in vitro) were performed in this position. If the position is changed to upright, the compliance values and divisions must be adjusted, because they vary with patient position $[35,52]$ and influence the CSF dynamics. A pressure sensor can be added to the end of the spinal canal to investigate pressure dynamics with changing hydrostatics. Furthermore, we hypothesize that the craniospinal compliance is time-dependent due to its viscoelastic properties or breathing and, thus, has to be considered when modeling the CSF dynamics. Regarding the in vitro model, we expect the mean ICP wave amplitude to decrease and the time of the maximum spinal CSF flow in a cranial direction to shift when the dynamic compliance is incorporated into the model. Moreover, our measurements have shown that the pressure and flow curves provide results in the physiological range with a 


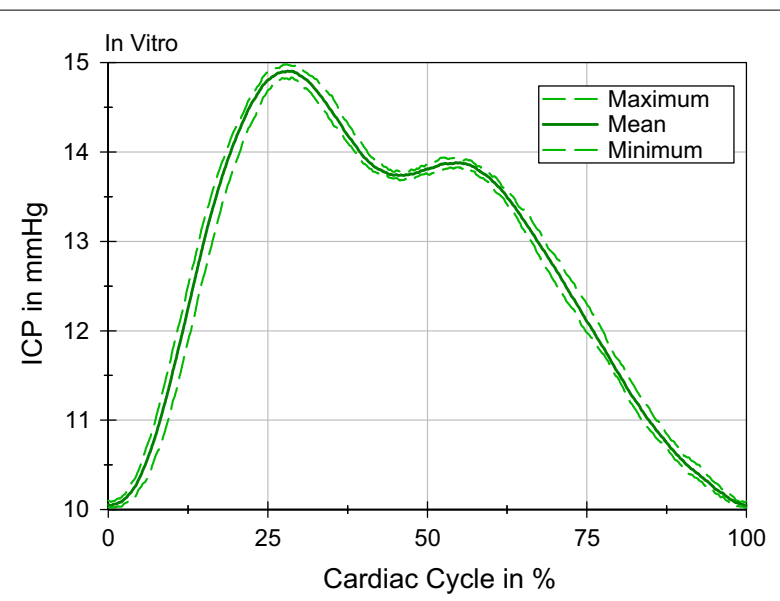

Fig. 7 In vitro ICP measured with the tip-catheter sensor in the ventricular system. The range of the same nine cardiac cycles as Fig. $6 \mathrm{~b}$ is shown

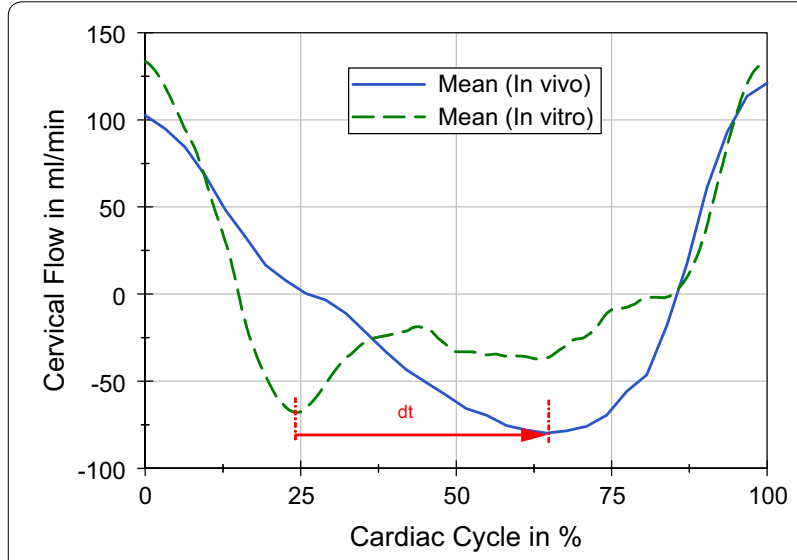

Fig. 8 Mean spinal CSF flows. This graph depicts the comparison of mean spinal CSF flows of the in vitro measurement (green) and the PC-MRI data of nine subjects (blue) derived from Fig. $6 a, b$

higher spinal compliance compared to the cranial compartment. However, this division is still being controversially discussed [31,34-36] and should be examined more closely in future measurements, specifically in terms of dynamic values and distribution.

In addition, it should be noted that the young and healthy volunteers (PC-MRI) were limited to nine subjects. However, they represent a healthy population [3]. Furthermore, the flow in the aqueduct should be measured, because its pulsatility and SV can be further indicators of NPH [53-56]. Another technical limitation is related to the flow measurement using an ultrasonic sensor. Although this method has the advantage of contactless measurements and deviations of $+/-6 \mathrm{ml} /$ min based on its technical specifications, due to the strongly pulsating flow, extrema show deviations of up to $21.09 \mathrm{ml} / \mathrm{min}$, while the mean values of flows over one CC only vary by $8.79 \mathrm{ml} / \mathrm{min}$.

The test bench can be extended due to the modular setup, which allows the addition of a variety of applications (e.g. breathing). In addition to investigating the pathogenesis of NPH, parameter analysis on spontaneous intracranial hypotension (a leak in the spinal canal) or syringomyelia (a cavity in the spinal canal) could be conducted in in vitro studies. Moreover, aging-related changes, such as a reduced blood flow, an AV delay [14], arterial stiffness [57], an increased resistance to outflow $[10,11]$ or a parenchymal liquefaction [58], can be analyzed. Furthermore, the test bench can be used to test alternative therapies and implants.

\section{Conclusion}

In conclusion, the in vitro results showed a good correlation with in vivo data and literature values regarding ICP and SVs. However, it emerged that the dynamic compliance cannot be neglected, especially for the analysis of the effects of high-pressure gradients and the strains on viscoelastic tissue. By integrating a dynamic compliance, known age-related or pathological changes in viscoelastic cerebrospinal tissue $[58,59]$ could be investigated. The main goals of our ongoing research are the sensitivity analyses of the blood dynamics by exchanging the cam disk or the frequency, the (dynamic) compliance behavior, the changed resistances (stenosis), the influence of hydrostatics and the integration of production and an adjustable absorption.

\section{Abbreviations}

AV: arteriovenous; CC: cardiac cycle; CSF: cerebrospinal fluid; ICP: intracranial pressure; MWA: mean wave amplitude; NI: national instruments; NPH: normal pressure hydrocephalus; p: pressure; PMMA: polymethylmethacrylate; PC-MRI: phase-contrast magnetic resonance imaging; SAS: subarachnoid space; SV: stroke volume; $\vee$ : volume.

\section{Authors' contributions}

$A B, K R$, CC, SL research; $A B$, KR conception of design; $O B$, AL analyzed data; $A B$, $O B, K R, C C, S L$ interpreted results of experiments; $A B$, KR prepared figures. $A B$, $\mathrm{OB}, C C, S L, K R$ edited and revised manuscript. All authors read and approved the final manuscript.

\section{Author details}

${ }^{1}$ Chair of Medical Engineering, Helmholtz-Institute for Biomedical Engineering, RWTH Aachen University, Pauwelsstraße 20, 52074 Aachen, Germany. 2 Department of Image Processing, University Hospital, E.A 7516, CHIMERE, Jules Verne University of Picardy, 80054 Amiens cedex, France. ${ }^{3}$ Chair for Medical Information Technology, Helmholtz-Institute for Biomedical Engineering, RWTH Aachen University, Pauwelsstraße 20, 52074 Aachen, Germany.

\section{Acknowledgements}

We thank National Instruments for supplying the acquisition hardware and the analysis software DIAdem. We thank Stefan Stürmer for the help with the constructional design. 


\section{Competing interests}

The authors declare that they have no competing interests.

\section{Availability of data and materials}

The part drawings of the constructional design are available from the corresponding author on request.

\section{Consent for publication}

Not applicable.

\section{Ethics approval and consent to participate}

The PC-MRI in vivo data is based on previously published papers $[3,38]$.

\section{Funding}

This project is funded in parts by the German Research Foundation (DFG RA $548 / 12-1)$.

\section{Publisher's Note}

Springer Nature remains neutral with regard to jurisdictional claims in published maps and institutional affiliations.

Received: 12 February 2019 Accepted: 15 April 2019

Published online: 29 April 2019

\section{References}

1. Oresković D, Klarica M. The formation of cerebrospinal fluid: nearly a hundred years of interpretations and misinterpretations. Brain Res Rev. 2010;64(2):241-62. https://doi.org/10.1016/j.brainresrev.2010.04.006.

2. Brinker T, Stopa E, Morrison J, Klinge P. A new look at cerebrospinal fluid circulation. Fluids Barriers CNS. 2014; https://doi. org/10.1186/2045-8118-11-10.

3. Balédent $\mathrm{O}$, Henry-Feugeas MC, Idy-Peretti I. Cerebrospinal fluid dynamics and relation with blood flow: a magnetic resonance study with semiautomated cerebrospinal fluid segmentation. Investig Radiol. 2001;36(7):368-77.

4. Hladky SB, Barrand MA. Mechanisms of fluid movement into, through and out of the brain: evaluation of the evidence. Fluids Barriers CNS. 2014;11(1):26. https://doi.org/10.1186/2045-8118-11-26.

5. Brodbelt A, Stoodley M. Csf pathways: a review. Br J Neurosurg. 2007:21(5):510-20. https://doi.org/10.1080/02688690701447420.

6. Czosnyka M, Czosnyka Z, Momjian S, Pickard JD. Cerebrospinal fluid dynamics. Physiol Meas. 2004;25(5):51-76. https://doi. org/10.1088/0967-3334/25/5/R01.

7. Malm J, Eklund A. Idiopathic normal pressure hydrocephalus. Pract Neurol. 2006;6(1):14-27. https://doi.org/10.1136/jnnp.2006.088351.

8. Hakim CA, Hakim R, Hakim S. Normal-pressure hydrocephalus. Neurosurg Clin N Am. 2001;12(4):761-73.

9. Greitz D. Radiological assessment of hydrocephalus: new theories and implications for therapy. Neurosurg Rev. 2004;27(3):145-651667. https:// doi.org/10.1007/s10143-004-0326-9.

10. Albeck MJ, Skak C, Nielsen PR, Olsen KS, Børgesen SE, Gjerris F. Age dependency of resistance to cerebrospinal fluid outflow. J Neurosurg. 1998:89(2):275-8. https://doi.org/10.3171/jns.1998.89.2.0275.

11. Czosnyka M, Czosnyka ZH, Whitfield PC, Donovan T, Pickard JD. Age dependence of cerebrospinal pressure-volume compensation in patients with hydrocephalus. J Neurosurg. 2001;94(3):482-6. https://doi. org/10.3171/jns.2001.94.3.0482.

12. Satow T, Aso T, Nishida S, Komuro T, Ueno T, Oishi N, Nakagami Y, Odagiri M, Kikuchi T, Yoshida K, Ueda K, Kunieda T, Murai T, Miyamoto S, Fukuyama $\mathrm{H}$. Alteration of venous drainage route in idiopathic normal pressure hydrocephalus and normal aging. Front Aging Neurosci. 2017;9:387. https ://doi.org/10.3389/fnagi.2017.00387.

13. Wilkie KP. Cerebrospinal fluid pulsations and aging effects in mathematical models of hydrocephalus. Ph.D. thesis, University of Waterloo. 2010.

14. Stoquart-ElSankari S, Baleédent O, Gondry-Jouet C, Makki M, Godefroy O, Meyer M-E. Aging effects on cerebral blood and cerebrospinal fluid flows. J Cereb Blood Flow Metab. 2007;27(9):1563-72. https://doi. org/10.1038/sj.jcbfm.9600462.
15. Goffin C, Leonhardt S, Radermacher K. The role of a dynamic craniospinal compliance in NPH_a review and future challenges. IEEE Rev Biomed Eng. 2017;10:310-22. https://doi.org/10.1109/ RBME.2016.2620493.

16. Pagé G, Bettoni J, Salsac A-V, Balédent O. Influence of principal component analysis acceleration factor on velocity measurement in $2 \mathrm{D}$ and 4D PC-MRI. Magma (New York, N.Y.). 2018;31(3):469-81. https://doi. org/10.1007/s10334-018-0673-0.

17. Papaiconomou C, Zakharov A, Azizi N, Djenic J, Johnston M. Reassessment of the pathways responsible for cerebrospinal fluid absorption in the neonate. ChNS. 2004;20(1):29-36. https://doi.org/10.1007/s0038 1-003-0840-z.

18. Wakeland W, Goldstein B. A review of physiological simulation models of intracranial pressure dynamics. Comput Biol Med. 2008;38(9):102441. https://doi.org/10.1016/j.compbiomed.2008.07.004.

19. Kurtcuoglu V. Computational fluid dynamics for the assessment of cerebrospinal fluid flow and its coupling with cerebral blood flow. In: Miller K, editor. Biomechanics of the brain. Biological and medical physics, biomedical engineering. New York: Springer; 2011. p. 169-88.

20. Czosnyka M, Czosnyka ZH, Whitehouse H, Pickard JD. Hydrodynamic properties of hydrocephalus shunts: United kingdom shunt evaluation laboratory. J Neurol Neurosurg Psychiatry. 1997;62:43-50.

21. Schuhmann MU, Engel M, Runge L, Samii M, Brinker T. Application of clinically recorded icp patterns-an extension of conventional shunt testing. ChNS. 2000;16(12):856-61. https://doi.org/10.1007/s003810000 366.

22. Martin BA, Loth F. The influence of coughing on cerebrospinal fluid pressure in an in vitro syringomyelia model with spinal subarachnoid space stenosis. Cereb Fluid Res. 2009;6:17. https://doi. org/10.1186/1743-8454-6-17.

23. Martin BA, Labuda R, Royston TJ, Oshinski JN, Iskandar B, Loth F. Spinal subarachnoid space pressure measurements in an in vitro spinal stenosis model: Implications on syringomyelia theories. J Biomech Eng. 2010;132:111007.

24. Fahrig R, Nikolov H, Fox AJ, Holdsworth DW. A three-dimensional cerebrovascular flow phantom. Med Phys. 1999;26(8):1589-99. https://doi. org/10.1118/1.598672.

25. Bouzerar R, Czosnyka M, Czosnyka Z, Balédent O. Physical phantom of craniospinal hydrodynamics. Acta Neurochirurgica. 2012;113:65-9.

26. Bottan S, Poulikakos D, Kurtcuoglu V. Phantom model of physiologic intracranial pressure and cerebrospinal fluid dynamics. IEEE Trans BioMed Eng. 2012;59(6):1532-8. https://doi.org/10.1109/TBME.2012.21874 48.

27. Benninghaus A, Goffin C, Leonhardt S, Radermacher K. Functional modeling of the craniospinal system for in-vitro parameter studies on the pathogenesis of NPH. Curr Dir Biomed Eng. 2017; https://doi. org/10.1515/cdbme-2017-0173.

28. Loth F, Yardimci MA, Alperin N. Hydrodynamic modeling of cerebrospinal fluid motion within the spinal cavity. J Biomech Eng. 2001;123(1):71. https ://doi.org/10.1115/1.1336144

29. Martin BA, Reymond P, Novy J, Balédent O, Stergiopulos N. A coupled hydrodynamic model of the cardiovascular and cerebrospinal fluid system. Am J Physiol. 2012;302(7):1492-509. https://doi.org/10.1152/ajphe art.00658.2011.

30. Kerle H, Corves B, Hüsing M. Getriebetechnik: Grundlagen, Entwicklung und Anwendung UngleichmäSSig übersetzender Getriebe. überarbeitete und erweiterte auflage edn. 5th ed. Wiesbaden: Springer; 2015. https:// doi.org/10.1007/978-3-658-10057-5.

31. Tain R-W, Bagci AM, Lam BL, Sklar EM, Ertl-Wagner B, Alperin N. Determination of cranio-spinal canal compliance distribution by MRI: methodology and early application in idiopathic intracranial hypertension. JMRI. 2011:34(6):1397-404. https://doi.org/10.1002/jmri.22799.

32. Wagshul ME, Eide PK, Madsen JR. The pulsating brain: a review of experimental and clinical studies of intracranial pulsatility. Fluids Barriers CNS. 2011;8(1):5. https://doi.org/10.1186/2045-8118-8-5.

33. Bateman GA, Levi CR, Schofield P, Wang Y, Lovett EC. The venous manifestations of pulse wave encephalopathy: windkessel dysfunction in normal aging and senile dementia. Neuroradiology. 2008;50(6):491-7. https://doi. org/10.1007/s00234-008-0374-x 
34. Marmarou A, Shulman K, LaMorgese J. Compartmental analysis of compliance and outflow resistance of the cerebrospinal fluid system. J Neurosurg. 1975;43(5):523-34. https://doi.org/10.3171/jns.1975.43.5.0523.

35. Magnaes B. Clinical studies of cranial and spinal compliance and the craniospinal flow of cerebrospinal fluid. Br J Neurosurg. 1989;3(6):659-68.

36. Wåhlin A, Ambarki K, Birgander R, Alperin N, Malm J, Eklund A. Assessment of craniospinal pressure-volume indices. AJNR. 2010;31(9):1645-50. https://doi.org/10.3174/ajnr.A2166.

37. Citerio G, Piper I, Cormio M, Galli D, Cazzaniga S, Enblad P, Nilsson P, Contant $C$, Chambers I. Bench test assessment of the new raumedic neurovent-p ICP sensor: a technical report by the brainit group. Acta Neurochirurgica. 2004;146(11):1221-6. https://doi.org/10.1007/s0070 $1-004-0351-z$.

38. El Sankari S, Gondry-Jouet C, Fichten A, Godefroy O, Serot JM, Deramond H, Meyer ME, BALÉDENT O. Cerebrospinal fluid and blood flow in mild cognitive impairment and alzheimer's disease: a differential diagnosis from idiopathic normal pressure hydrocephalus. Fluids Barriers CNS. 2011;8(1):12. https://doi.org/10.1186/2045-8118-8-12

39. Alperin N, Lee SH, Sivaramakrishnan A, Hushek SG. Quantifying the effect of posture on intracranial physiology in humans by MRI flow studies. JMRI. 2005;22(5):591-6.

40. Yoshida KK, Takahashi H, Saijo M, Ueguchi T, Tanaka H, Fujita N, Murase K Phase-contrast mr studies of CSF flow rate in the cerebral aqueduct and cervical subarachnoid space with correlation-based segmentation. Magn Reson Med Sci. 2009;8(3):91-100. https://doi.org/10.2463/mrms.8.91.

41. Anile C, Portnoy HD, Branch C. Intracranial compliance is time-dependent. Neurosurgery. 1987;20(3):389-95.

42. Bergsneider M. Chapter 15, hydrocephalus new theories and new shunts. Clin Neurosurg. 2005;52:120.

43. Gupta S, Soellinger M, Boesiger P, Poulikakos D, Kurtcuoglu V. Threedimensional computational modeling of subject-specific cerebrospinal fluid flow in the subarachnoid space. J Biomech Eng. 2009;131(2):1-11.

44. Balédent O, Gondry-Jouet C, Meyer M-E, de Marco G, Le Gars D, HenryFeugeas M-C, Idy-Peretti I. Relationship between cerebrospinal fluid and blood dynamics in healthy volunteers and patients with communicating hydrocephalus. Investig Radiol. 2004;39(1):45-55. https://doi. org/10.1097/01.rli.0000100892.87214.49.

45. Capel C, Baroncini M, Gondry-Jouet C, Bouzerar R, Czosnyka M, Czosnyka Z, Balédent O. Cerebrospinal fluid and cerebral blood flows in idiopathic intracranial hypertension. In: Heldt T, editor. Intracranial pressure and neuromonitoring, vol. XVI. Cham: Springer; 2018. p. 237-41.

46. Harary M, Dolmans RGF, Gormley WB. Intracranial pressure monitoringreview and avenues for development. Sensors (Basel, Switzerland). 2018;. https://doi.org/10.3390/s18020465.

47. Albeck MJ, Borgesen SE, Gjerris F, Schmidt JF, Sorensen PS. Intracranial pressure and cerebrospinal fluid outflow conductance in healthy subjects. J Neurosurg. 1991;74(4):597-600. https://doi.org/10.3171/ jns.1991.74.4.0597.
48. Sakka L, Coll G, Chazal J. Anatomy and physiology of cerebrospinal fluid. Eur Ann Otorhinolaryngol Head Neck Dis. 2011;128(6):309-16. https://doi. org/10.1016/j.anorl.2011.03.002.

49. Kiefer M, Steudel W-I. Moderne hirndruckmessung grundlagen und praxis. Der Unfallchirurg. 2002;105(7):578-86. https://doi.org/10.1007/ s00113-002-0469-5.

50. Eide PK. The correlation between pulsatile intracranial pressure and indices of intracranial pressure-volume reserve capacity: results from ventricular infusion testing. J Neurosurg. 2016;125(6):1493-503. https:// doi.org/10.3171/2015.11.JNS151529.

51. Ringstad G, Lindstrøm EK, Vatnehol SAS, Mardal K-A, Emblem KE, Eide PK. Non-invasive assessment of pulsatile intracranial pressure with phasecontrast magnetic resonance imaging. PlOS ONE. 2017;12(11):0188896. https://doi.org/10.1371/journal.pone.0188896.

52. Gehlen M, Kurtcuoglu V, Schmid Daners M. Is posture-related craniospinal compliance shift caused by jugular vein collapse? A theoretical analysis. Fluids Barriers CNS. 2017; https://doi.org/10.1186/s12987-017-0053-6.

53. Bateman GA. The pathophysiology of idiopathic normal pressure hydrocephalus: cerebral ischemia or altered venous hemodynamics? AJNR. 2008;29(1):198-203. https://doi.org/10.3174/ajnr.A0739.

54. Bateman GA, Levi CR, Schofield P, Wang Y, Lovett EC. The pathophysiology of the aqueduct stroke volume in normal pressure hydrocephalus: can co-morbidity with other forms of dementia be excluded? Neuroradiology. 2005;47(10):741-8. https://doi.org/10.1007/s00234-005-1418-0.

55. Luetmer PH, Huston J, Friedman JA, Dixon GR, Petersen RC, Jack CR, McClelland RL, Ebersold MJ. Measurement of cerebrospinal fluid flow at the cerebral aqueduct by use of phase-contrast magnetic resonance imaging: technique validation and utility in diagnosing idiopathic normal pressure hydrocephalus. Neurosurgery. 2002;50(3):534-43. https://doi. org/10.1097/00006123-200203000-00020.

56. Qvarlander S, Ambarki K, Wåhlin A, Jacobsson J, Birgander R, Malm J, Eklund A. Cerebrospinal fluid and blood flow patterns in idiopathic normal pressure hydrocephalus. Acta Neurol Scand. 2017;135(5):576-84. https://doi.org/10.1111/ane.12636.

57. Fonck E, Feigl GG, Fasel J, Sage D, Unser M, Rüfenacht DA, Stergiopulos N. Effect of aging on elastin functionality in human cerebral arteries. Stroke. 2009;40(7):2552-6. https://doi.org/10.1161/STROKEAHA.108.528091.

58. Sack I, Beierbach B, Wuerfel J, Klatt D, Hamhaber U, Papazoglou S, Martus $P$, Braun J. The impact of aging and gender on brain viscoelasticity. Neurolmage. 2009;46(3):652-7. https://doi.org/10.1016/j.neuroimage 2009.02.040.

59. Freimann FB, Streitberger K-J, Klatt D, Lin K, McLaughlin J, Braun J, Sprung C, Sack I. Alteration of brain viscoelasticity after shunt treatment in normal pressure hydrocephalus. Neuroradiology. 2012;54(3):189-96. https:// doi.org/10.1007/s00234-011-0871-1.

60. Zweckberger K, Sakowitz OW, Unterberg AW, Kiening KL. Intrakranielle druck-volumen-beziehung. physiologie und pathophysiologie. Der Anaesth. 2009;58(4):392-7. https://doi.org/10.1007/s00101-009-1522-3.

Ready to submit your research? Choose BMC and benefit from:

- fast, convenient online submission

- thorough peer review by experienced researchers in your field

- rapid publication on acceptance

- support for research data, including large and complex data types

- gold Open Access which fosters wider collaboration and increased citations

- maximum visibility for your research: over 100M website views per year

At BMC, research is always in progress.

Learn more biomedcentral.com/submissions 